\title{
Application of electromagnetic induction in processing and heat machining of metals - implemented automated technological processes
}

\author{
Zastosowanie indukcji elektromagnetycznej \\ w przetwórstwie i obróbce termicznej metali - wdrożone, \\ zautomatyzowane procesy technologiczne
}

\begin{abstract}
KRZYSZTOF KONOPKA ZDZISŁAW KONOPKA *
\end{abstract}

DOI: https://doi.org/10.17814/mechanik.2017.11.165
The paper presents four implemented automated systems for thermal machining and processing of metals using induction heating, where precise control of numerous process parameters plays an important role.

KEYWORDS: induction heating, induction hardening, induction brazing, continuous casting, automation of induction heating processes

In industrial practice, induction heating is used more and more often for the formation of forms and properties of metals, which displace gas or oil heating. The processes of quenching, tempering, annealing, brazing, welding, melting and casting are areas where the use of induction heating continues to increase. Manufacturers are increasingly demanding the precision of shaping the molds, the precise definition of mechanical properties of products (especially those for the automotive and aviation industry) and their reproducibility in mass production, as well as control and archiving of production parameters - this entails the need for automated and robotic systems. While designing and implementing metal heat treatment systems, simulation programs can be supported to pre-select parameters of the equipment, but only practical tests can verify these parameters.

The authors decided to share their experiences with the use of inductive heating on an example of some solutions of implemented automated heating, hardening, annealing, tempering, welding, rolling, melting and casting. Next, four automated systems for thermal treatment and processing of metals with induction heating are presented:

- automated induction heating in hardening, tempering, welding and annealing operations - especially used in the manufacture of power transmission components in cars;

- automatic technology line for hot screw rolling;

- automated induction brazing process;

- automatic continuous melting and casting line for copper alloy rolls manufacture.

* Dr inż. Krzysztof Konopka (krzysztof.konopka@polsl.pl) - Politechnika Śląska, Instytut Metrologii, Elektroniki i Automatyki; dr inż. Zdzisław Konopka (z.konopka@elkon.com.pl) - Zakład Elektroniki i Automatyki Przemysłowej „ELKON” Sp. z o.o.
Automated induction heating in hardening, tempering, welding and annealing operations

The automated process line, consisting of 4 heat treatment slots - welding, annealing of welds, hardening and tempering after welding - is shown schematically in fig. 1 . The drawing shows one of the controller screens, where the processing line is displayed.

Components to be treated are supplied via the input trays and then placed in a welding device S1. Welding of elements is robotized, and the process is preceded by induction heating of welded spots. The parameters of the welding process were chosen by repeated attempts.

The next step is induction annealing of welds performed on the position S2. Then, the industrial robot transfers a part to a device for induction hardening S3. The hardening profile, hardening depth and hardness distribution in the quenched zone are strictly defined and imposed by the manufacturer the exemplary requirements are shown in fig. 2 . Such a profile can only be obtained by an automated device that provides speed control and, in addition, movement of the inductor in 2 axes during hardening and zone programming of hardening parameters. The resulting quenched area shown in fig. $3 a$.

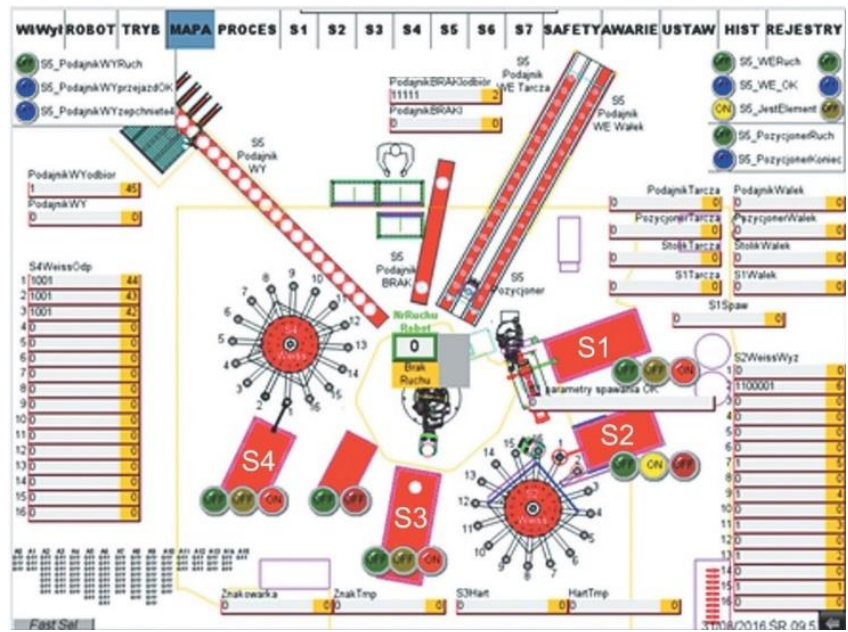

Fig. 1. Screenshot of the main line controller of technological line with visible layout of the line modules 


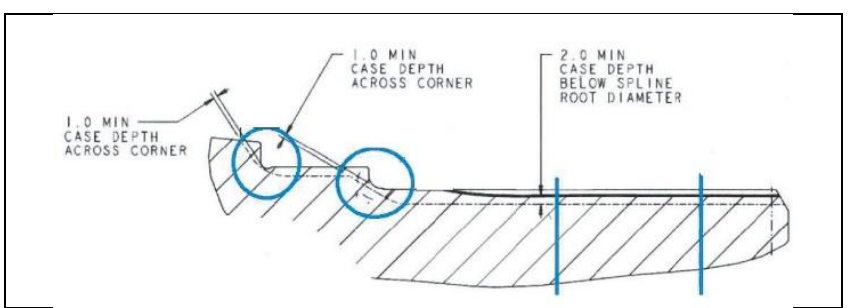

Fig. 2. Required course of the quenched zone along the shaft

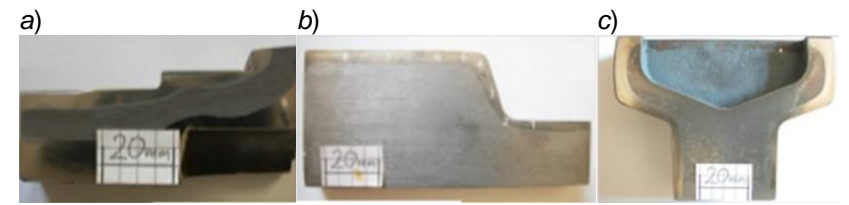

Fig. 3. Exemplary shapes of hardened profile

After hardening, the robot moves the component to the device, in which the inductive tempering occurs, and after this operation - for marking and on output conveyor.

Processes of induction heating prior to welding, weld annealing or induction tempering are not complex and their automation is mainly related to the maintenance of a specified temperature value within a time regime. Much more difficult to automate is the induction surface hardening process with a complicated course of the hardened zone. As seen in fig. 2, the quenched element has different diameters and the required hardened zone includes both the diameters and transition surfaces between them. It should be kept in mind that not every form of hardening zone is possible to obtain as a result of induction hardening, which results from the nature of physical phenomena used in the process. The skin effect phenomenon is particularly important here, which causes the induced current to flow at the outermost diameter. This results in, among others, in that the change in diameter of the outer edge of the step has a tendency to overheating, whereas the recess is unheated. Similar phenomena occur in the case of various types of grooves in the hardened surface.

Generally, there are growing requirements for induction hardening of the surface of various irregular shapes that have been hardened by classical method - carburizing. Induction hardening is cheaper, and with appropriate control of temperature, makes possible to control the depth of heating and maintaining these parameters in mass hardening.

The process of induction hardening is difficult and often impossible to simulate in its entirety, because it is influenced by many factors. Although a description of the physical or chemical phenomena occurring is generally recognized, the amount of data that must be included in the simulation model complicates calculations very much [1, 5]. In practice, commercially available simulation programs are specialized to 2 simultaneous calculation of selected parameters. For this reason, in practice, induction hardening parameters are usually determined experimentally.

Complex courses of quenching zones can be obtained in devices with a wide range of positioning of the inductor in relation to the hardened element (due to servo drives), which allow programming of the motion parameters and heating power, and in particular cases - by installing generators with a wide frequency range of the inductor current. This allows hardening of complex shapes in 3 dimensions (e.g. cap, gears - by means of single teeth, polyline, toothed rails, toothed wheel rims methods [2, 3]). It is often necessary to properly model the inductor and use magnetic concentrators. Examples of obtained shapes of the hardened zone are shown in fig. 3.

\section{Automatic technological line for screw hot rolling}

Presented technological line was built for the purpose of screw rolling on steel rods with a diameter of $\varnothing 20 \div 30 \mathrm{~mm}$.
The line consists of induction heater, rolling mill, rod feeder and conveyor receiving the screwed rods. The view of the technological line is shown in fig. $4 a$, and the finished product - in fig. $4 b$.
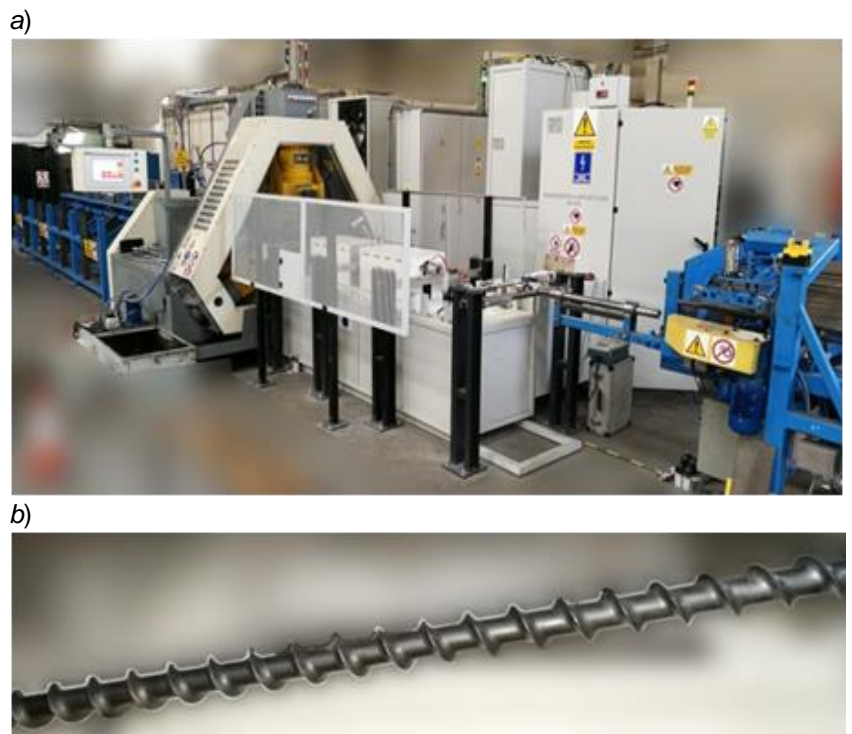

Fig. 4. Automatic technological line for hot screw rolling (a) and finished product $(b)$

Temperature adjustment must take into account: variations in heating conditions - due to uneven filling of the inductor at the beginning and end of rolling, changes in the speed of the element moving and magnetic change of the material during heating. Significant effect on the operation of the system is exerted by temperature of the rod during rolling, since plasticity of the heated steel causes elongation of the element during rolling, thus changing the linear speed of the rolled rod, while the measured rotational speed of the rollers remains constant, which in turn adversely affects the temperature of the rod (change of duration the rod remains in the inductor). This positive feedback has to be compensated by the regulator. The main problem in the system of rod temperature control is a large thermal inertia of the object, and the fact that the effect of the regulation is only measured at the output of the heated rod from the inductor. In spite of the dynamics of changes in the disturbance parameters and inertia of the control object at a temperature of $1200{ }^{\circ} \mathrm{C}$, accuracy of $2 \%$ for maximum deviation and $0.7 \%$ for average deviation was obtained. The temperature of the rod at the entrance of the mill was measured by the pyrometer. The time course of rod temperature before rolling is shown in fig. 5 .

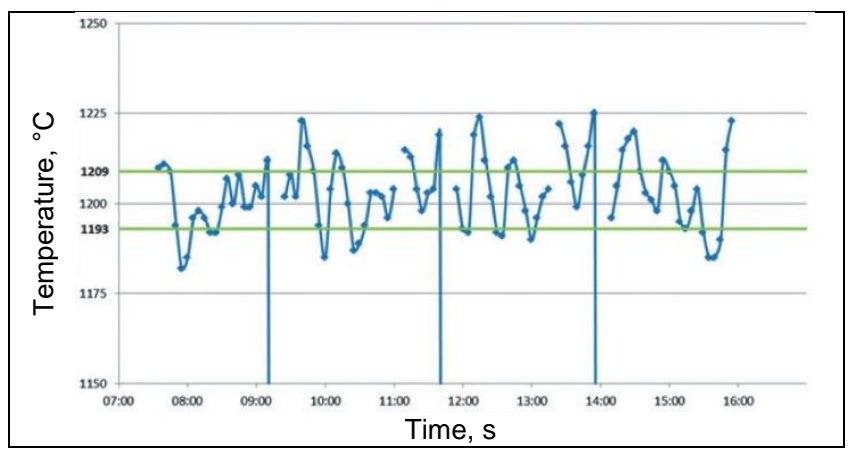

Fig. 5. Timing of rod temperature before rolling

\section{Automated induction soldering process}

Induction soldering is becoming more and more popular in automated mass production, in which - as far as practicable - suppresses the flame soldering. Induction heating is a parameter that determines the efficiency of 
operations and minimizes costs. Variety of inductive soldering applications is very large, but the authors were confined to presenting 2 automatic soldering processes.

- Longitudinal soldering of copper tubes. This method is widely used in the production of refrigeration systems for refrigerators and freezers. The copper tube, usually $\varnothing 6$ or $\varnothing 8 \mathrm{~mm}$ in diameter, is soldered longitudinally with a tube of diameter of $\varnothing 1.8 \mathrm{~mm}$ - at a length of $4 \div 6 \mathrm{~m}$. An example of this solution is shown in fig. 6 . The soldering steps are automatic, according to the program, i.e. at a predetermined speed of soldering and power of the heater. After heating the tubes and applying the solder feeder, tubes are compressed with rollers until solidification of the alloy. All the technological operations are carried out according to the developed program.

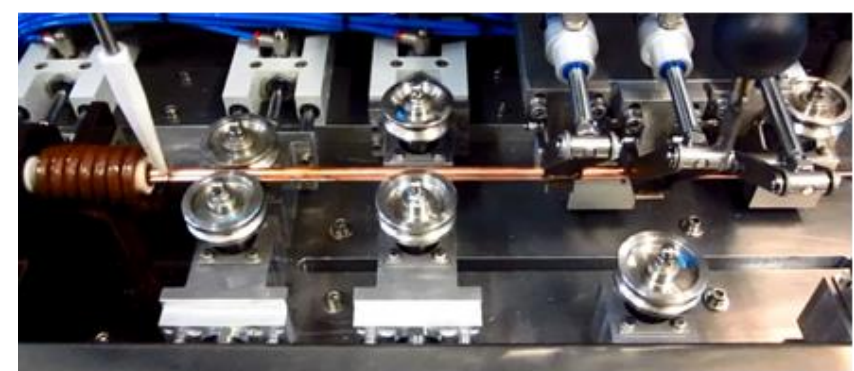

Fig. 6. Fragment of device for longitudinal soldering the copper tubes There are visible: heating element, solder feeder, compressing rollers and tube pulling gripper

- Soldering the aluminum elements. This process is also automated (due to a mass production) and allows soldering the aluminum valves for aluminum tubes at right angles. The problem with heating results from the unevenness of the shape and weight of the valve in relation to the shape and weight of the tube. Soldering is performed using AISi12 solder having a melting point lower by only $30{ }^{\circ} \mathrm{C}$ than the melting point of aluminum. View of the inductively soldered element is shown in fig. $7 \mathrm{a}$. In designing apparatus for induction soldering, the most important is to choose the shape of the inductor (fig. $7 b$ ) providing a temperature distribution that the solder will be drawn into the required connection point (place of a higher temperature).

a)

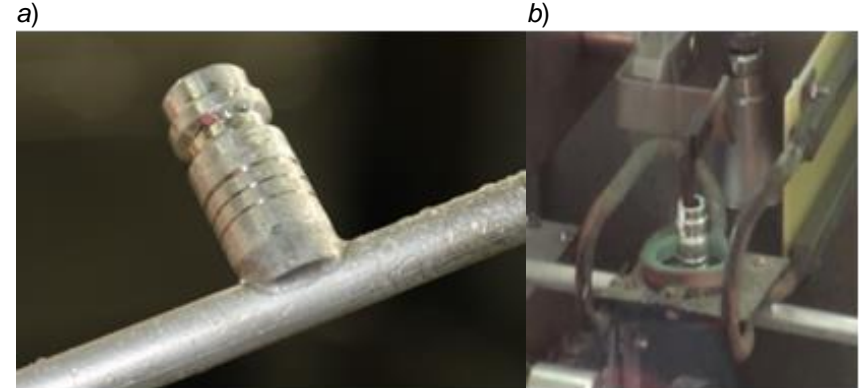

Fig. 7. Soldering the aluminum components: a) finished product, $b$ ) inductor during soldering

\section{Automatic line for continuous melting and casting the rollers of non-ferrous metal alloy}

Continuous casting of metals is already a classic. On the other hand, innovative technical solutions of the presented device, which were developed for the dissipated casting of products manufactured by the continuous casting method, are of great interest as the higher level of processing of metals obtained in secondary processing (dominated by small and medium companies). Features of this system are: low investment costs, short payback period, ease of operation and carrying out repairs, ease of changing the production profile and making small series production, sustainability, comfort, spatial compactness.

It should be emphasized that for recycling companies, continuous casting is a challenge. This process requires a detailed knowledge in the field of casting engineering and mechatronics.

In the presented line - in accordance with the classical continuous casting method - a molten metal or alloy with a given chemical composition and temperature [4] is prepared in the melting induction furnace. The molten metal is poured into a cast furnace, where two crystallizers are built in the crucible, forming two independent tracks for casts production (fig. 8). The performance of each track is approximately 100 $\mathrm{kg} / \mathrm{h}$ of a roller with a diameter of $30 \mathrm{~mm}$. After cooling the casting (in the secondary cooling system), it passes through the drawing system to the cast cutting system to the required length of the casting and then deposited in the casting store. Each casting track has its own process control system with programmed parameters: metal temperature in the casting furnace, drawing speed, and timing of drawing, stopping and reversing of the roller. The following are also programmed: temperature of water cooling the crystallizers, secondary cooling intensity, and temperature of the casting crucible and casting furnace. Continuous casting process automation enables programming of this process for a variety of casting technologies (depending on the type of metal and chemical composition of its alloys) and, moreover, (as in the present solution) - cutting to a desired sections and storage.

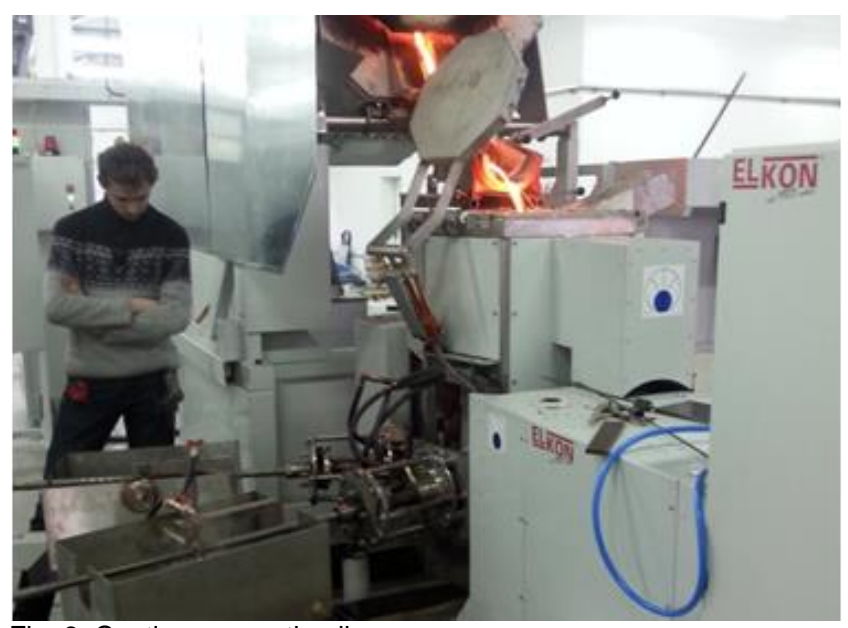

Fig. 8. Continuous casting line

\section{Conclusions}

The common feature of the presented industrial automation systems for the use in devices based on electromagnetic induction is that these are not concepts but solutions implemented in the industrial realm. The implementation of any such system requires the ongoing resolution of many engineering and scientific problems.

\section{REFERENCES}

1. Smalcerz A., Przyłucki R., Konopka K., Fornalczyk A., Ślezok M. „Multivariant calculations of induction heating process". Archives of Materials Science and Engineering. 58, 2 (2012): pages 177-181.

2. Konopka K. „Hartownia do badań precyzyjnego sterowania procesem hartowania indukcyjnego". Napędy i Sterowanie. 16, 1 (2014): pages 8692.

3. Konopka K. „Hartowanie z precyzyjnym sterowaniem procesem hartowania indukcyjnego". Stal Metale \& Nowe Technologie. 9/10 (2014): pages 140-142.

4. Konopka K. „Układ pomiarowy do badania zależności dynamiki mieszania płynnego metalu od pola magnetycznego" PAK. 60, 2 (2014): pages 87-89.

5. Barglik J., Smalcerz A., Wieczorek T. „Modelowanie matematyczne procesu nagrzewania indukcyjnego powierzchniowego". Zeszyty Naukowe. Elektryka. Politechnika Łódzka. 125 (2013): pages 185-192. . 